\title{
Recycling and Value-added Design of Discarded Wooden Furniture
}

\author{
Danren Yang, and Jiangang Zhu * \\ In the process of the "green revolution", individuals have realized the \\ importance of recycling waste materials. However, with ongoing \\ individual changes in lifestyle, the huge resource of discarded wooden \\ furniture is still considerably underutilized. This paper aims to provide \\ new ideas for the recycling of discarded wooden furniture and to create \\ added value to used furniture. Based on the summarization of existing \\ recycling technology and methods, the diversified innovation and reuse \\ of discarded wooden furniture integrating the current aesthetic and \\ demand of people from multiple aspects are analyzed for the purpose of \\ revealing the hidden value of waste materials. Waste recycling is of great \\ importance to the country and enterprises in line with the concept of \\ circular economy. For the sake of further excavating the hidden value of \\ discarded wooden furniture products, the additional in-depth research in \\ optimizing and upgrading green production and manufacturing in \\ furniture industry is called for in the paper.
}

Keywords: Discarded furniture; Recycling; Value-added design

Contact information: College of Furnishings and Industrial Design, Nanjing Forestry University, Nanjing, 210037, China; *Corresponding author: 1048316284@qq.com

\section{INTRODUCTION}

With the improvement of living standards and the popularity of "fast fashion", the styles and pursuits of individuals tends to be real-time and diversified. Discarded furniture has been replaced by more popular and novel products, and the amount of discarded wooden furniture has been increasing year by year. Wood is an important material in the production of furniture. Approximately 60 million pieces of discarded furniture are abandoned in China every year, which amounts to approximately $8500 \mathrm{~m}^{3}$ (Sun and Shi 2006). In Britain, approximately 1.6 million tons of furniture and large garbage are thrown away every year, most of which are buried in landfill sites or incinerated in incinerators (Chamberlin and Thomas 2015). Furniture products have a varied shelf life, i.e., wooden furniture could be renewed range anywhere from just one year to twenty years. Therefore, discarded furniture is a type of solid waste that is not only large in quantity, but also difficult to deal with.

Studies have shown that the use of $100 \%$ waste wood is more sustainable, and recycling, as the last link of life cycle design, needs to play a key link role (Iritani et al. 2015). In Europe, recycling wood from products to improve the utilization of forest biomass is considered as one of the most important strategic objectives and research areas (Daian and Ozarska 2009). In the entirety of Europe, 35 million to 40 million tons of waste wood reaches the end of its useful life every year (Mergner 2019). In recent years, some scholars in the field of ecological sustainability have put forward relevant opinions on product life (Cooper 2005; Nes 2010; Cooper and Nishijima 2018), the product life 
cycle (Kim et al. 2014; Tao and Yu 2018), and cradle-to-cradle design (Llorach-Massana et al. 2015; Kausch and Klosterhaus 2016), which have been gradually received and applied. Designers are following the steps of the "green revolution", seeking to upgrade the beauty of various waste materials (Hebrok 2016; Krystofik et al. 2018). As furniture in many cases is a durable good that could live for centuries with proper care, wear and decay do not fully account for its disposal. Prolonging the service life of products primarily lies in the durability, repairability, modular structure of materials, etc., while the influence of living habits, family structure, and emotion on products is still hidden, which is a considerable blind spot (Chapman 2010; Fletcher 2012; Hebrok 2014).

Through the review of relevant literature, the authors have found that remanufacturing has developed in various industrial fields. To some extent, it fosters innovation and has the potential to grow markets and increase profits (Otieno et al. 2020). In the field of furniture manufacturing and design, the concepts of the sustainable design and life cycle design of office furniture is widely used, which also indicates that the application of the principle of a circular economy to upgrade and innovate the design of used furniture is conducive to creating new businesses and improving the adaptability of products (Bosch et al. 2017). In this sector, opportunities related to the Circular Economy model are mostly linked to eco-design, use of renewable materials, reduction of emissions, and use of environmental certifications (Federlegno 2016). While the European small and medium-sized enterprises are mostly conscious of the opportunities deriving from Circular Economy, some barriers to this new model have been identified (D'Anghela et al. 2019). Similarly, the current implementation of China's circular business models is still at an early stage, and there are obstacles in many links. Barriers to the consideration of used furniture products are identified under the technologies barriers sector as well (Li 2016; Xiong et al. 2017). In recent years, many researchers have also focused on the recycling and reprocessing of waste wood materials to make full use of and realize value-added products, e.g., recycling waste wood to make wood-based panels (Ming et al. 2009; Yichao et al. 2015), and sawdust to achieve thermoplasticization through the benzoylation process (Üner et al. 2016). Exploring the remanufacturing of wood furniture products not only alleviates the resource gap and reduces the waste, but also contributes to the construction of national environmental awareness (Yi et al. 2019).

The texture and warmth of beautiful, adaptable, and durable wood furniture can bring life to spaces, and such an approach has been shown to be good for people's wellbeing and the environment. According to the survey, some people in society accept the reuse of used furniture. The green marketing in the current era has also improved the recognition of recycling and recreation among the social groups. As such, the important question of how can recycling conform to current trends and realize the high-quality utilization of discarded furniture, so as to increase its value, is the focus of the current life cycle design of wooden furniture products.

In terms of the recycling and reuse of discarded wooden furniture, more developed countries have formed a relatively complete system (Alexander and Smaje 2007). In the United Kingdom, there are many systematic second-hand furniture websites, and each city has its own special household waste recycling center. There are many charity thrift stores in the streets and alleys, whose profits will be used for charity, that predominantly rely upon recycling. Many cities in Europe and the United States regularly hold discarded furniture fairs, large furniture abandonment days, garage fairs, etc. The recycling system of IKEA is also gradually forming. By paying for recycling second-hand furniture, it not only drives people to take care in how they dispose of 
second-hand furniture, but also stimulates public interest in innovation and transformation, which gives new vitality to old homes. In terms of used furniture recycling in China, it has also started to move towards a systematic, standardized, and green system In addition, the second-hand furniture trading market of Hong Kong is booming. With the help and guidance of the government, Guangzhou, Shenzhen, and other places have started to establish disposal centers for discarded furniture resources. Changsha used to disassemble discarded wooden furniture and use it to create outdoor public furniture for resting.

In order to explore the recycling methods of discarded wooden furniture and the possibility of value-adding based on the concept of the product life cycle design, this research summarizes the common recycling methods of the current common wood furniture. The application of the principle of a circular economy and a combination of wooden culture, i.e., the love and emotions of individuals in terms of wooden furniture, as well as considering the fusion of culture and the comprehensive utilization of structure, material, etc., can help to explore the old ways and transitioning to innovation. This is in accord with the aesthetic and functional requirements of the present, in order to show the hidden value of scrap material, and realize value-added discarded wooden furniture.

\section{DESIGN CONSIDERATIONS}

\section{Recycling of Discarded Wooden Furniture}

Current situation of discarded wooden furniture

Presently, the circulation of discarded furniture in the market can be primarily divided into three categories, which are traditional solid wood furniture, removable structural furniture, and mixed material furniture. Traditional solid wood furniture primarily refers to the mortise and tenon structure, which is the most valuable furniture sold in one piece. Presently, the primary circulation of this type of furniture is still to enter the secondary market for resale and collection. The removable structural furniture is primarily the panel type, which is easy to produce, sell, disassemble, and assemble. This type of furniture conforms to the current advocated concept and popular trend and is easy to be reconstituted after recycling. This type of furniture has a high level of reuse. Mixed material furniture is primarily designed and manufactured in combination with other materials, e.g., metal, resin, glass, etc., and it is not suitable for separation. Such furniture has a high processing cost and may introduce difficulties and dangers during processing.
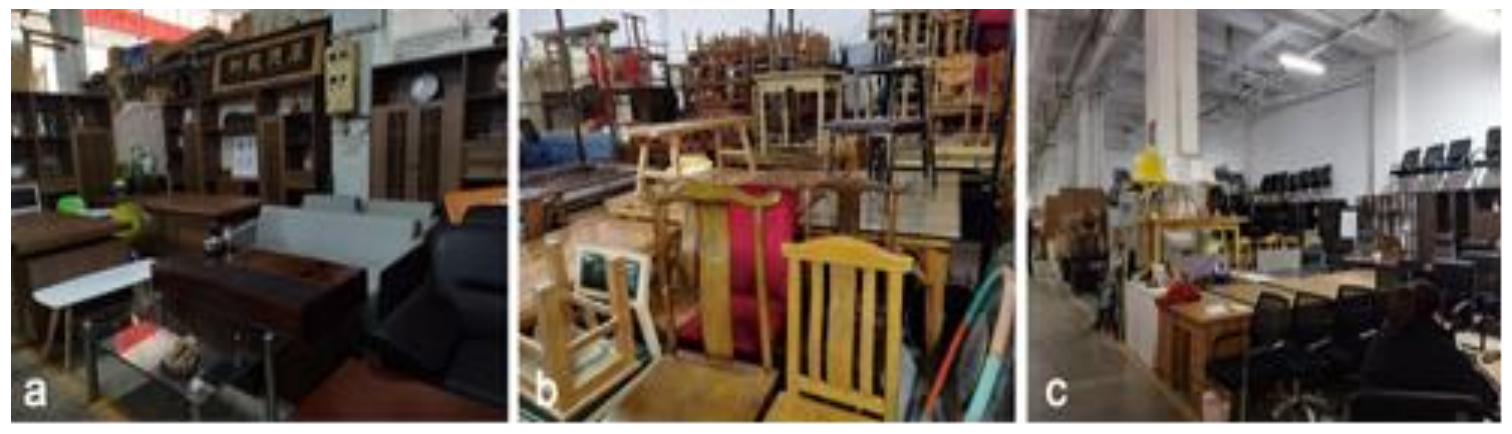

Fig. 1. (a), (b) and (c) show discarded furniture sold in a furniture second-hand market in Nanjing (photo source: Taken by the author) 
Discarded furniture causes a waste of resources and may bring some environmental pollution. Figure 1 shows second-hand wooden furniture in a second-hand market. Furniture flowing into the secondary market is cheap, and the buyers are primarily rental buyers or those who have temporary needs, e.g., for filming, etc. Many products accumulate dust, and the whole market is gradually becoming ignored. However, burning second-hand furniture as fuel will cause serious pollution to the environment. Thus, how to deal with the problems caused by the current consumption pattern and how to make the huge resource reusable has become a new social problem.

\section{Recycling}

Currently, recycling primarily includes discarded furniture substrates, with four primary methods: energy utilization, renovation and renovation, recycling, and other special ways (Sun and Shi 2006). Energy utilization refers to its direct use as fuel or processing into new fuels, e.g., wood coal production and use. Reconstruction and renovation refers to its reuse after some simple repairs or mechanical processing. With this method, the preservation of good furniture after decontamination, repair, and other treatment allows for its continued usage. Similarly, in this way, large, heavy furniture materials can be reduced and thinned to continue to use. In addition, it can also be machined into a certain plate specification and reused in the production of furniture. Recycling refers to the classification of waste wood substrate, its decomposition or crushing into wood chips, wood fiber, etc., and then further processing into fiberboard, particleboard, and other artificial boards to be used in a series of furniture production process. In the field of wood processing, wood-plastic composite materials have been produced and processed. Discarded wooden furniture can also realize its deep value in this way. Other special methods include the following: being made into controlled-release fertilizer shells made from wood residues, which can control the speed of fertilizer release (Fu et al. 2010) and being made into crude wood vinegar (Cao and Wang 2014), which has bactericidal and antibacterial effects, which can be used in agriculture, fishery, and other aquaculture productions.

\section{Value-Added Design}

Principles of value-added design

Monomer and system

Based on the perspective of modern design, this paper analyzes the degree of damage to recycled wood and classifies and matches the discarded wooden furniture in terms of its properties, color, modeling, etc., which are primarily reflected in the aesthetic and functional aspects. It transforms simple reusage into a product systematic design based on waste substrate, so that the recycling design of discarded wooden furniture forms a specific system compared to being sporadic and independent.

\section{Whole and detail}

One of the major factors affecting the utilization of waste wood in the current market is its degree of acceptance by the public. Therefore, the various requirements of different consumers in terms of the texture, color, and shape of recycling products, must be met in accordance with the acceptance degree of the current users. In addition, other factors, e.g., ergonomics and design psychology, must be considered, with a focus on how to realize the functional embodiment of the products after the recycling of discarded wooden furniture. 


\section{Function and emotion}

The interaction between people and furniture often has emotional interpretation. Discarded wooden furniture in general has some "relationship" with the user itself, i.e., there is a certain amount of emotion retained in its memory. This emotion is most strongly tied to original furniture, and in the era of consumption, nostalgia became one of the most vulnerable emotions in terms of consumer content ( $\mathrm{Fu} \mathrm{2015).} \mathrm{Therefore,} \mathrm{to}$ increase the potential demand, markets should pay attention to any emotional resonance that can be found in the product (Chen et al. 2019). In addition, value-added design can be personalized for users, by innovating and recreating the discarded furniture according to the needs of the user, preserving past memories, and making up for emotional regrets.

\section{Process technology and design concept}

Technology and design complement each other, allowing for the full utilization of the various material characteristics of recycled discarded wooden furniture substrates, and the usage of wood plastic composite and glued laminated technology. This, combined with the current consumer demand and cognitive research results, allows for different degrees of combination and reconstruction, in order to meet the preferences of different groups of people, and transfer a new life concept and cultural connotation. As such, technology and design work together in terms of green production to realize the added value of the innovation and reuse of discarded wooden furniture during the green era.

\section{Factors Influencing Value Added Design}

Consumer groups

Young people have a high degree of recognition for the innovation and reconstruction of used furniture, and it is necessary to pay more attention to the multiple innovations in appearance, design, and function. Middle-aged and elderly groups pay attention to practicality and emotional retention and as such avoid adding value via means of additional decoration and painting. Therefore, it is necessary to conduct market research and design positioning according to consumer groups and divide them into multi-level user groups to explore the preferences of different users in various aspects, e.g., subjectivity and objectivity, and dig out different key points, so as to expand product recognition groups and consumer groups and extend the product service cycle of valueadded design.

\section{Modeling}

According to the required concept, function, style, etc., the key design elements should be extracted, in order to break the constraints of the original modeling, reorganize different types of furniture components, highlight the theme of the redesign, and provide serialization and richness. In addition, wood plastic composite, lamination, and other plate manufacturing technologies also contribute to the recycling of discarded wooden furniture innovation and upgrading by creating furniture with better performance than wood in terms of design and production, so that the old objects present a new style while simultaneously reducing the cost of maintenance during its later stage.

\section{Color}

Recycled discarded wooden furniture has a wide range of base materials, which can be targeted to retain their own color or to carry out the corresponding coloring treatment to highlight the texture of the wood used. In addition, color can be added to the 
original substrate by means of coating, decorative paper reengineering, etc. to achieve overall innovation, so as to realize color appreciation.

\section{Material}

Multiple fusion in terms of discarded wooden furniture as the base material, adding other materials, e.g., metal, glass, stone, etc., is utilized to break the "old", enriching the decorative effect and structural strength. In addition, special attention is given to the leading role of waste furniture, when the diversified materials are adopted. Other materials are only used to play an auxiliary role. For example, the combination of Ming and Qing style wooden furniture with metal and resin, the combination of simplicity and straightness with softness and bending, and the modern combination of square and circle and hardness and softness.

\section{Structure}

The upgrading of the connection technology in modern furniture design and the production of batch mechanization in enterprises provides additional methods for the connection of furniture structures. Taking into account the national and global standardization and approval of the " $32 \mathrm{~mm}$ " system, as well as the multiple types of furniture panels in panel furniture, the design of standard and universal panels can be restructured to save processing time and reduce costs. At the same time, this method does not stick to the traditional tenon and mortise form and considers new combination methods, using modern technology. This simplifies the interface difficulty, reduces the loss percentage of wood, and creates removable and stable structure furniture, which is convenient for the life cycle of the product to run in a closed loop.

\section{Culture}

How to take the cultural customs and lifestyle of Chinese people as the starting point and the traditional Chinese cultural connotations as the basis and integrate these traditional elements into value-added design by modernizing them is a serious concern in terms of recycling furniture. By doing so, recycled furniture can cater to the upsurge of the recognition of the current group in Chinese culture, so as to create a series of green furniture with Chinese style and realize its value-added.

\section{Scope}

The recycling of discarded wooden furniture is not limited to furniture and home furnishing, and it can be involved in a wide range of fields. The recycling of waste wood should not only be limited to a single frame but should be carried out in an overall plan with reasonable planning and utilization, so as to realize the overall value-added of waste wood and improve the recyclability of resources.

\section{RESULTS AND DISCUSSION}

\section{Value-added Design for Wood Furniture Recycling}

Discarded furniture as a new design element, not only fits green production, but also expresses feelings, and can add different colors to replicate various aspects of life. In recent years, there have been a lot of B \& B (Bed \& Breakfast), restaurants, and cafes that recall childhood and nostalgia. In addition, the current fashion trend of "retro art" or 
"industrial Loft", driven by a "literary youth economy", discarded furniture with design sense has also become one of the best partners for atmosphere cultivation and environment creation. As shown in Fig. 2, according to the existing technology and processes, discarded wooden furniture that can be recycled after classification can be combined with the key elements of value-added design to carry out appropriate valueadded design. To retain renovation, it is necessary to integrate "nostalgic" elements to the greatest extent as well as retain its form and structure, as shown in Fig. 3a. Deconstruction and reorganization primarily focus on disassembly, and how to reflect different feelings via fusion, so as to make it fresh. It can be considered as combining the recycled furniture with other materials to reflect a rhythm and order. This process is simple, highly operable, and unique, as shown in Fig. $3 \mathrm{~b}$ and 3c. Crushing and regeneration changes the original type of wood, so that the definition of "old" changes, make it change as a whole, so as to form a new material with better performance, e.g., the preparation and application of new paper artificial boards, wood plastic composites, and wood ceramics (as shown in Fig. 3d and 3f). However, the processing equipment, precision, and processing skills needed for this process have higher requirements and must meet a certain standard. These enterprises, factories, and other systematic institutions are more suitable for processing and production. Artistic sublimation items are primarily the non-practical functional products, e.g., sculptures and displays, which have high decorative and atmosphere building effects (as shown in Fig. 3e). They express the emotion of old things and memories. In addition, discarded furniture can be renewed via DIY (do it yourself) creation, according to the ideas of an individual. Of course, the application of discarded furniture should not be limited to furniture but should broaden the value-added field. Discarded wooden furniture should be used as the base material in home life, work, and other occasions, to make creative and novel wood products, as well as to realize its hidden powerful functional value, e.g., as the base material for cameras, acoustics, pet nests, etc. (as shown in Fig. $3 \mathrm{~g}$ and $3 \mathrm{~h}$ ).

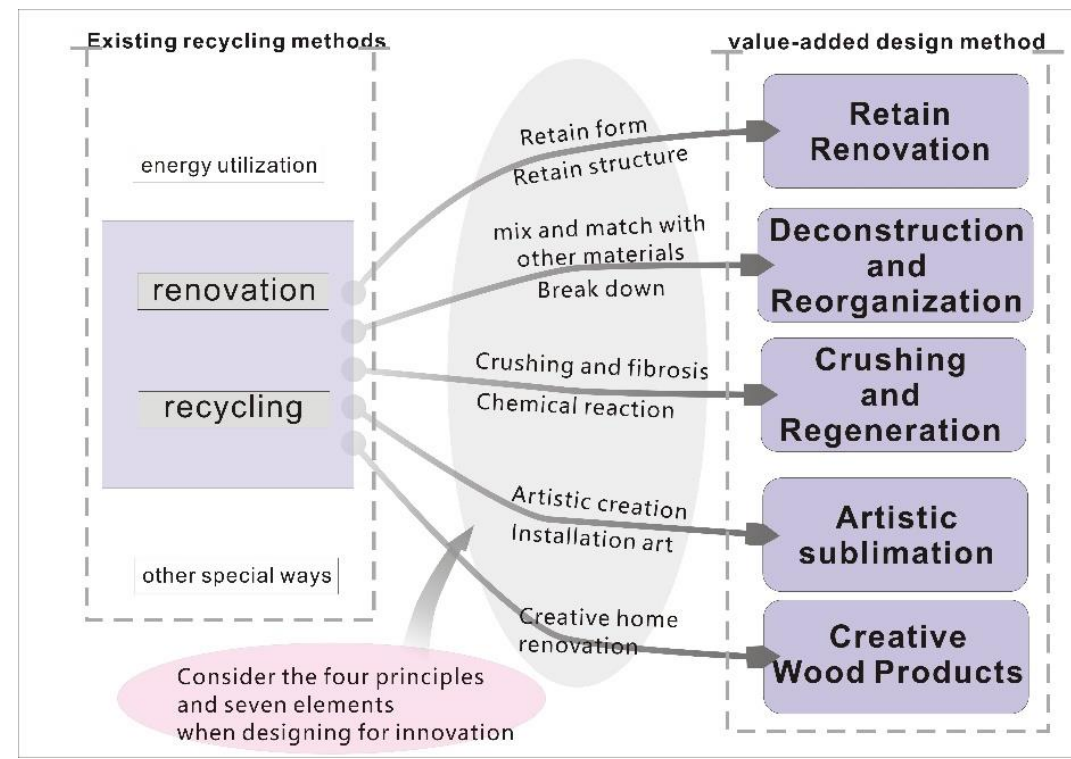

Fig. 2. Value-added method. The figure shows a series of value-added design methods formed after transformation, innovation and creative conception on the basis of the original recycling method. (picture source: drawn by the author) 


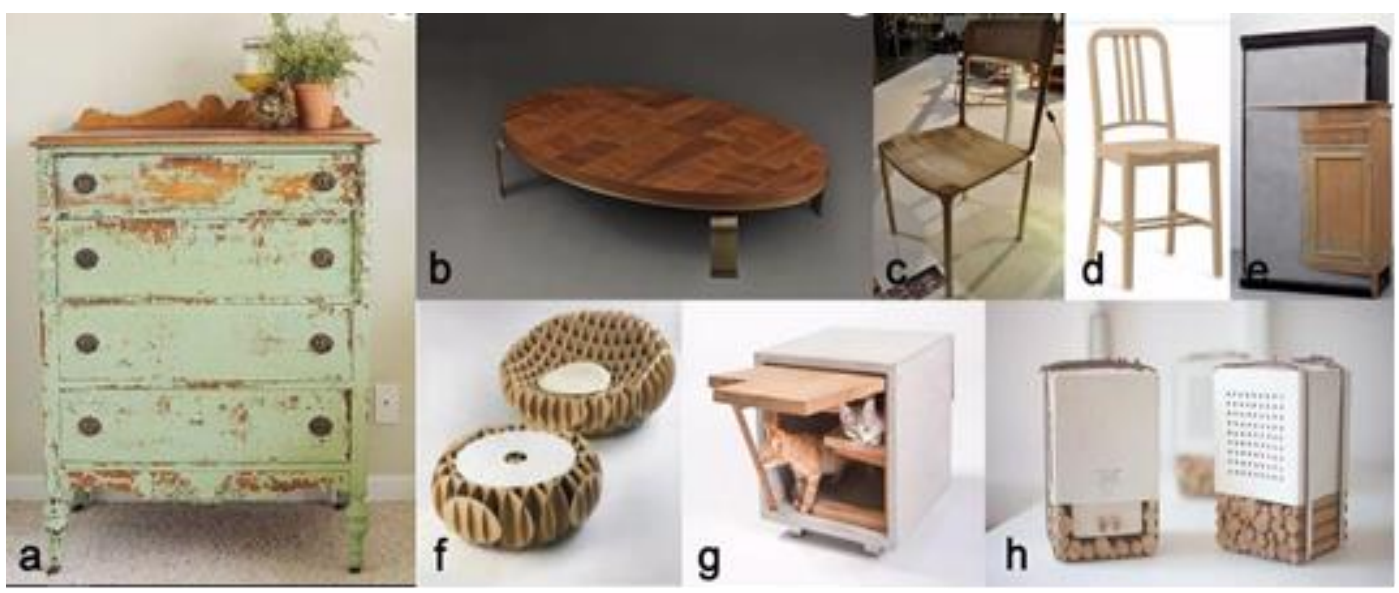

Fig. 3. Value-added design case. (a). The old furniture achieves a retro American rustic feel by scraping away some of the original finish. Both (b) and (c) are composed of wooden boards and wood blocks. (b) is made of spliced wooden surfaces and bronze legs. The warmth of wood and hardness of metal blend well. (c) is made by cool Solutions, a design company, using recycled wood from shipping pallets. (d) is the navy chair of Emeco, which is made of wood fiber and polypropylene. The brand adheres to the concept of environmental protection and uses the waste of modern consumption and industrial waste as the main raw materials to process and manufacture furniture products. (e) is a sculpture product created together with plaster and cement for shabby storage cabinets. (f) shows that the discarded wooden furniture is made into paper artificial boards after being crushed. $(\mathrm{g})$ and $(\mathrm{h})$ shows the use of discarded wooden furniture as the base material in home life, work and other occasions, making creative and novel wood products to realize its hidden powerful functional value.

(picture source: (a). https://ro.pinterest.com/dorin01380/mobilier-vopsit/

(b). http://huaban.com/pins/1037618596/

(c). https://www.contemporist.com/category/design/page/285/

(d). https://www.topnotchbitches.com/outdoor-furniture/emeco-111n-flint-111-navy-counter-stoolflint-gray

(e). https://sumally.com/p/2534559

(f). https://www.homemag.sk/1576/chcete-papierovy-nabytok/

(g).https://www.jiemian.com/article/399281.html?spm=smwp.content.content.2.1536364800036h OtrcXw

(h). https://www.pinterest.com/pin/261138478367608038/)

The green manufacturing technology system of the furniture industry in China is still relatively lacking (Xiong et al. 2020). The research, application, and implementation of design and manufacture based on abandoned wooden furniture is a complex system project, involving the cognition, classification, design, and processing of waste wood materials, which requires the joint participation and support of the government, enterprises, and scientific research institutions. The government should strengthen publicity and guidance to popularize the public awareness of recycling. At the same time, strengthening the control of the recycling and utilization system will help to standardize and systematize recycling. A corresponding public database of discarded wooden furniture can be established, and a production model can be set up to optimize profit and improve efficiency, which would also be convenient for designers and manufacturers to select materials (Lin et al. 2020). Enterprises and institutions should take the lead in reusing discarded wooden furniture during each link of the production process, especially in the disassembling of the product in terms of standardization, generalization, and modularization. By doing so, they can realize large-scale mass production as well as optimize market technology, thus generating greater benefits, 
improving overall efficiency, and reducing waste. Designers should integrate green design into the system design of products to realize the hidden value of furniture. Consumers can also perform DIY and simple value-added reuse, e.g., the deconstruction and reorganization of waste substrates in the home.

Currently, the corresponding domestic system is under construction, and valueadded research about discarded wooden furniture and the recycling and utilization of addition products all need further in-depth research and planning. This will help perpetuate the green cycle, and it is also a major goal and trend of furniture design today and in the future.

\section{CONCLUSIONS}

This study investigated various innovation and transformation methods applied to realize the value of waste wood furniture. Based on the research results, the following conclusions are presented:

1. The following should be considered in the value-added design after the recycling of waste furniture: four principles in aspects of monomer and system, whole and detail, function and emotion, process technology and design concept; and the seven elements in aspects of consumer groups: consumer groups, modeling, color, material, structure, culture, and scope. Designers and enterprises can be inspired to consider the value of products in a comprehensive, multilevel, multifaceted way.

2. The five value-added design methods of used furniture have been summarized in this article, and the existing recycling technologies are innovated and upgraded.

3. Making full use of waste wood furniture resources is beneficial to form a closed loop to ensure life cycle design and reflect the circular economy requirements, which is conducive to promoting national ecological development and corporate image.

4. This work was conducted with the aim of investigating the recycling and value-added design of discarded wooden furniture, but the related industry management and system planning needs to be further researched according to practical application.

\section{ACKNOWLEDGMENTS}

The authors are grateful the support of the Joint Research program of the Sinoforeign Cooperation in Running Schools of Jiangsu Province, China.

\section{REFERENCES CITED}

Alexander, C., and Smaje, C. (2007). "Evaluating third sector reuse organisations in the UK: Case-studies and analysis of furniture reuse schemes," Resources, Conservation \& Recycling 52(5), 719-730. DOI: 10.1016/j.resconrec.2007.09.005

Bosch, T., Verploegen, K., Grösser, S. N., and Gu, v. R. (2017). "Sustainable furniture that grows with end-users," in: Dynamics of Long-Life Assets, S. N. Grösser, A. Reyes-Lecuona, and G. Granholm (eds.), Springer Publishing, New York, NY. 
Cao, H., and Wang, H. (2014). "Research progress of preparation and refining of wood vinegar," Guangdong Chemical Industry 41(4), 37-38.

Chamberlin, L., and Thomas, S. (2015). "The great recovery - Rearranging the furniture," (https://www.thersa.org/reports/the-great-recovery-rearranging-thefurniture), Accessed 08 Sep 2015.

Chapman, J. (2010). "Subject object relationships and emotionally durable design," in: Longer Lasting Solutions: Advancing Sustainable Development through Increased Product Durability, T. Cooper (ed.), Ashgate (Gower), London, United Kingdom.

Chen, Y., Yang, Y., and Zhang, Z. (2019). "Study on small-diameter wood scrimber and furniture design," Journal of Forestry Engineering 4(1), 155-159.

Cooper, T. (2005). "Slower consumption - Reflections on product life spans and the 'throwaway society'," Journal of Industrial Ecology 9(1-2), 51-67. DOI: $10.1162 / 1088198054084671$

Cooper, T., and Nishijima, D. (2018). "The growing significance of product life-spans as a variable when addressing environmental impacts," Journal of Life Cycle Assessment Japan 14(1), 55-63. DOI: 10.3370/lca.14.55

Daian, G., and Ozarska, B. (2009). "Wood waste management practices and strategies to increase sustainability standards in the Australian wooden furniture manufacturing sector," Journal of Cleaner Production 17(17), 1594-1602. DOI: 10.1016/j.jclepro.2009.07.008

D'Anghela, M, Bravi, L, and Murmura. F (2019). "Wood furniture SMEs approaches towards circular economy: A literature review," in: Proceedings of the $1^{\text {st }}$ Conference on Quality Innovation and Sustainability (ICQIS2019), Valença, Portugal, pp. 54-60.

Federlegno, S. (2016). "Il Made in Italy abita il futuro," Il legno arredo verso l'economiacircolare,(http://www.symbola.net/html/article/IlmadeinItalyabitailfuturoI ILegnoArredoversoleconomiacircolare), Accessed 04 Sept 2019.

Fletcher, K. (2012). "Durability, fashion, sustainability: The processes and practices of use," Fashion Practice 4(2), 221-238. DOI: 10.2752/175693812X13403765252389

Fu, L., Wan, Y., and Tang, L. (2010). "The conception of coat of slow/controlled release fertilizers made by wood remainder," Practical Forestry Technology 11(11), 50-52.

Hebrok, M. (2014). "Design for longevity: Taking both the material and social aspects of product-life into account," Journal of Design Research 12(3), 204-220. DOI: 10.1504/JDR.2014.064232

Hebrok, M. (2016). "Where furniture goes to die. Designing for sustainable behaviour in a practice perspective," Techniques \& Culture 65-66, 1-18.

Iritani, D. R., Silva, D. A. L., Saavedra, Y. M. B., Grael, P. F. F., and Ometto, A. R. (2015). "Sustainable strategies analysis through life cycle assessment: A case study in a furniture industry," Journal of Cleaner Production 96, 308-318. DOI: 10.1016/j.jclepro.2014.05.029

Kausch, M. F., and Klosterhaus, S. (2016). "Response to 'Are cradle to cradle certified products environmentally preferable? Analysis from an LCA approach," Journal of Cleaner Production 113, 715-716. DOI: 10.1016/j.jclepro.2015.11.008

Kim, S. J., Kara, S., and Kayis, B. (2014). "Economic and environmental assessment of product life cycle design: volume and technology perspective," Journal of Cleaner Production 75, 75-85. DOI: 10.1016/j.jclepro.2014.03.094

Krystofik, M., Luccitti, A., Parnell, K., and Thurston, M. (2018). "Adaptive remanufacturing for multiple lifecycles: A case study in office furniture," Resources Conservation and Recycling 135, 14-23. DOI: 10.1016/j.resconrec.2017.07.028 
Lin, C.-W. R., Chen, M.-T., Tseng, M.-L., Chiu, A. S. F., Ali, M. H., and Chang, K.-H. (2020). "Profit maximization for discarded furniture recycled in Taiwan using cradleto-cradle production programming," Mathematical Problems in Engineering 2020, 115. DOI: $10.1155 / 2020 / 2948049$

Llorach-Massana, P., Farreny, R., and Oliver-Sola, J. (2015). "Are cradle to cradle certified products environmentally preferable? Analysis from an LCA approach," Journal of Cleaner Production 93, 243-250. DOI: 10.1016/j.jclepro.2015.01.032

Li, Y.-L. (2016). Developing Circular Business Models in Chinese Furniture Industry, Master's Thesis, IIIEE, Lund University, Lund, Sweden.

Mao, Y., Min, L., and Wu, Z. (2015). "Recycling and value-added design of old wooden furniture," Packaging Engineering 36(14), 14-17.

Mergner, S. (2019). "Recycled wood: Waste or resource?," (https://www.wbpionline.com/features/recycled-wood-waste-or-resource-6971058/), Accessed 7 February 2019.

Ming, C., Jianhua, L., and Zhihui, W. (2009). "Review of China' s furniture industry manufacturing styles," China Wood Industry 23(6), 21-24.

Nes, N. V. (2010). "Understanding replacement behaviour and exploring design solutions," in: Longer Lasting Products: Alternatives to the Throwaway Society, T. Cooper (ed.), Ashgate (Gower), London, United Kingdom.

Otieno, W., Chen, P.-H., and Chen, K.-J. (2020). "Assessing the remanufacturability of office furniture: A multi-criteria decision-making approach," Journal of Remanufacturing (Prepublish), Published 28 March 2020. DOI: 10.1007/s13243-02000079-7

Sun, H., and Shi, X. (2006). "Circular utilization of recycled wood material furniture," Forestry and Grassland Machinery 23(1), 32-35.

Tao, J., and Yu, S. (2018). "Product life cycle design for sustainable value creation: Methods of sustainable product development in the context of high value engineering," Procedia CIRP 69, 25-30. DOI: 10.1016/j.procir.2017.11.099

Üner, B., Köse, G., Yürümez, Y., Yalçın, Ö. Ü., and Akgül, M. (2016). "Wood waste turned into value added products: Thermal plasticization by benzylation process," Drvna Industrija 67(4), 315-322. DOI: 10.5552/drind.2016.1534

Xiong, X., Ma, Q., Yuan, Y., Wu, Z., and Zhang, M. (2020). "Current situation and key manufacturing considerations of green furniture in China: A review," Journal of Cleaner Production 267, 1-15. DOI: 10.1016/j.jclepro.2020.121957

Xiong, X., Guo, W., Fang, L., Zhang, M., and Wu, Z. (2017). "Current state and development trend of Chinese furniture industry," Journal of Wood Science 63, 433 444. DOI: $10.1007 / \mathrm{s} 10086-017-1643-2$

Yi, L., Wu, Z., and Wei, X. (2019). "Review of the application of life cycle assessment to furniture industry," World Forestry Research 32(2), 56-60.

Article submitted: June 16, 2021; Peer review completed: August 21, 2021; Revised version received and accepted: August 29, 2021; Published: August 31, 2021.

DOI: 10.15376/biores.16.4.6954-6964 